\title{
Vegetative Compatibility and Pathogenicity of Verticillium dahliae from Spearmint and Peppermint
}

\author{
L. I. Douhan and D. A. Johnson, Department of Plant Pathology, Washington State University, Pullman 99164- \\ 6430
}

\begin{abstract}
Douhan, L. I., and Johnson, D. A. 2001. Vegetative compatibility and pathogenicity of Verticillium dahliae from spearmint and peppermint. Plant Dis. 85:297-302.

The vegetative compatibility of 128 isolates of Verticillium dahliae from spearmint and peppermint in the western and midwestern United States was determined. Nit mutants were used to assign isolates to vegetative compatibility groups (VCGs). All isolates were assigned to VCG 2B except for one assigned to VCG 2A and two assigned to VCG 4A. VCG 2 isolates were found in all commercial mint growing regions, while the two VCG 4A isolates originated from southern Idaho. Pathogenicity assays on mint were performed using isolates from mint and other hosts, and pathogenicity assays were conducted on the potato cultivar Russet Norkotah using mint and potato isolates. Isolates originating from mint were significantly more aggressive on mint than were other host isolates, indicating that mint isolates were host-adapted. VCG 4A isolates from mint and potatoes were significantly more aggressive on potato than VCG 4B potato isolates and VCG $2 \mathrm{~B}$ mint isolates. We speculate that the low VCG diversity of mint isolates may be due to the introduction of a single aggressive strain into Washington State mint fields via infected rhizomes.
\end{abstract}

Additional keywords: Mentha, pathotypes, Verticillium wilt

Verticillium wilt, caused by the vascular wilt pathogen Verticillium dahliae Kleb., is an economically important disease of peppermint (Mentha $\times$ piperita L.) and Scotch spearmint $(M . \times$ gracilis Sole $)$, two of the three main mint species produced commercially for essential oils in western and midwestern states. The third mint species, Native spearmint (M. spicata L.), can be infected by $V$. dahliae but is less susceptible to wilt damage than the other two mint species (4). During the late 1940s, the majority of mint production shifted from midwestern to western states due to Verticillium wilt $(23,27)$. V. dahliae reduces oil production by limiting plant growth or killing plants. Verticillium wilt is managed by planting disease-free mint rhizomes in noninfested soil and rotating with nonsusceptible hosts $(16,25)$. In Washington and Idaho, mint is occasionally grown in soil previously planted with susceptible crops such as potato. Knowledge of host-specificity of strains of $V$. dahliae would assist in making disease management decisions.

$V$. dahliae isolates are thought to have a wide host range and lack host specificity. However, pathotypes have been reported

Corresponding author: D. A. Johnson

E-mail: djohnsn@wsu.edu

Accepted for publication 21 November 2000.

Publication no. D-2000-1220-02R

(C) 2001 The American Phytopathological Society for potato $(22,29,36)$ and cotton $(34)$, and physiological races have been shown for tomato (1). Nelson (27) considered the microsclerotial form of Verticillium from peppermint to be host-specific and reclassified $V$. dahliae (18) as V. albo-atrum var. menthae. Subsequent work demonstrated that host specificity of $V$. dahliae isolates was not as specific as Nelson (27) had reported $(14,15,17,19)$.

Vegetative compatibility is a useful marker for determining the genetic structure of some fungal populations (24) and, in fungi, is controlled by multiple genetic loci. Hyphae of strains that have identical alleles present at all compatibility loci can anastomose to form a viable heterokaryon. Isolates that share compatibility loci and can anastomose with one another belong to a subpopulation designated as a vegetative compatibility group and are genetically isolated from other VCGs $(24,30)$.

Four or more VCGs $(21,35)$ have been detected among $V$. dahliae isolates from various hosts $(3,8,11,13,21,22,26,29,30$, $32,37,38)$. Several studies have correlated VCGs with pathogenicity on different hosts $(11,22,36)$. For example, Joaquim and Rowe (22) separated VCG 4 isolates into two subgroups, VCG 4A and VCG 4B. The subgroups were classified as pathotypes and were separated based on pathogenicity experiments on potatoes and the positive reactions with different tester strains. When inoculated to potatoes, VCG $4 \mathrm{~A}$ isolates were more aggressive than VCG 4B isolates.
Although a few mint isolates have been included in previous vegetative compatibility studies $(20,32)$, VCG diversity in $V$. dahliae populations infecting mint has not been studied. Additionally, the level of host adaptation in $V$. dahliae populations associated with mint is not clear. Knowledge of VCG diversity and host adaptation would be useful in developing wiltresistant mint species, designing crop rotations for mint, and determining inoculum sources for $V$. dahliae in mint fields. Mint is rotated with potato in Washington State, and a better understanding of host adaptation and aggressiveness of $V$. dahliae isolates from both hosts would help devise better disease management strategies. The objectives of this study were to: (i) determine VCG diversity of $V$. dahliae isolates collected from naturally infected spearmint and peppermint plants grown throughout the western and the midwestern United States; and (ii) evaluate pathogenicity and aggressiveness of $V$. dahliae isolates from mint and other hosts on mint and potato. A preliminary report of this investigation has been published (12).

\section{MATERIALS AND METHODS}

Isolates of $\boldsymbol{V}$. dahliae. $V$. dahliae isolates from mint and other host plants were obtained from plants collected in the field and from collaborators. Mint plants showing Verticillium wilt symptoms were collected from randomly selected commercial mint fields in Washington, Idaho, and Oregon between June and September 1996. One diseased stem per plant was surfacesterilized with a $10 \%$ commercial bleach solution for 2 min, rinsed with sterile water, and crushed inside a polyethylene plastic bag using a vise. Two milliliters of sterile distilled water was added to the bag, and 0.25 to $0.50 \mathrm{ml}$ of sap solution was spread onto NPX medium (6) and incubated at room temperature $\left(21\right.$ to $\left.24^{\circ} \mathrm{C}\right)$ for 10 to 15 days. One isolate per stem with up to three isolates per field were randomly chosen from NPX plates to be used in vegetative compatibility analyses. Monoconidial isolates were stored on sterilized filter paper and kept at $5^{\circ} \mathrm{C}$.

Vegetative compatibility. Nitrate nonutilizing mutants (nit) were generated using a modified version of Puhalla's technique (31). V. dahliae isolates were incubated for 1 to 2 weeks at room temperature (21 to $24^{\circ} \mathrm{C}$ ) on cornmeal agar (Difco Laboratories, Detroit, MI) amended with dextrose 
( $2 \mathrm{~g} /$ liter) and potassium chlorate (25 to 40 $\mathrm{g} /$ liter). Conidia from chlorate-resistant sectors were streaked onto Minimal Medium (31) with nitrate as the sole source of nitrogen. Nit mutants were identified by their thin, expansive, appressed growth. One nit mutant was obtained from each wild-type isolate. Monoconidial cultures of each mutant were stored as described above. Nit mutants were separated into two phenotypic classes, nitl and NitM (9), based on their growth on Basal Media (21) amended with one of four different nitrogen sources: sodium nitrate, hypoxanthine, ammonium-tartrate, or uric acid.

Each nit mutant of $V$. dahliae was paired with a known nitl and NitM VCG testers designated as OARDC tester strains obtained from R. C. Rowe (Ohio State University, Wooster). The tester strains used for each VCG were the following: VCG 1, V-44; VCG 2A, PH; VCG 2B, 115; VCG 3, PCW; VCG 4A, BB; VCG 4B, S39. Mutants were paired with each tester at least twice. Additionally, eight nit mutants were tested for complementation across a polycarbonate membrane to ensure that the positive reaction resulted from heterokaryon formation and not cross-feeding. In these tests, each mutant was paired with each tester, which was separated by a 47mm-diameter polycarbonate membrane with a pore size of $0.2 \mu \mathrm{m}$ (Poretics Corp., Livermore, CA).

Pathogenicity assays. Isolates from mint and other hosts were tested for patho- genicity and aggressiveness on mint and potato in four greenhouse experiments. The first three experiments were conducted on two mint species, Black Mitcham peppermint and Scotch spearmint, and were designated as experiments 1 to 3 . The fourth experiment was conducted on the potato cultivar Russet Norkotah and was designated as experiment 4. Each experiment was conducted twice using the same isolates and hosts. Isolates from mint and other hosts were used for the three mint experiments, and isolates from mint and potato were used for the experiment on potato. Experiment 1 included $18 \mathrm{mint}$ isolates and five isolates from other hosts and was replicated four times (Table 1). In experiment 1 , a greater number of mint isolates were used to evaluate the range of variation among isolates from mint. Experiments 2 and 3 included four mint isolates and four isolates from other hosts (Tables 2 and 3), and experiment 4 included four mint isolates and four potato isolates (Table 4). Experiments 2 and 3 were replicated eight times, and experiment 4 was replicated 10 times. Additional replicates were added to experiments 2 to 4 to increase statistical power. Three isolates in experiment 1 were not used when the experiment was repeated due to the lack of availability of inoculum but were used in experiment 2. Isolates for each experiment were chosen by species origin and geographic location. Treatments were arranged in the greenhouse in a randomized com- plete block to reduce variability among the experimental units within a block.

Peppermint and Scotch spearmint plants were clonally propagated in flats by cutting the top 7.5 to $10 \mathrm{~cm}$ of stems from Verticillium-free repository mint stock, dipping cut stems into Root tone (NAA, Madison, GA), and planting the stems in sterilized potting soil. The cuttings were grown in the greenhouse until the plants were approximately 3 to $5 \mathrm{~cm}$ tall and had well-developed root systems. Potato plants were prepared by planting a $3 \times 1.5 \mathrm{~cm}$ bud piece from generation-one certified seed tubers into sterilized potting soil and grown in the greenhouse until the plants were 8 to $10 \mathrm{~cm}$. Seventyfive percent of the potatoes from the lot used in this experiment were tested and found to be free of $V$. dahliae. The tubers were tested by placing a small sliver of the stem end onto NPX media and examining the plates for $V$. dahliae at approximately 10 to 14 days.

Conidial inoculum of $V$. dahliae isolates were prepared by placing colonized agar plugs from wild-type isolates into $125 \mathrm{ml}$ of Czapeks-Dox broth (Difco) or potato dextrose broth (Difco) and incubating at room temperature on a shaker for 7 days. Conidia were filtered through cheesecloth, quantified with a hemacytometer, and adjusted with sterile water to a concentration of $5 \times 10^{5}$ conidia per $\mathrm{ml}$ for experiments 2 and 3 and $1 \times 10^{6}$ conidia per $\mathrm{ml}$ for experiments 1 and 4 . Preliminary data (not

Table 1. Mean disease severity values when spearmint and peppermint were inoculated with Verticillium dahliae isolates VCG 2B and VCG 4A from mint and other hosts in experiment 1

\begin{tabular}{|c|c|c|c|c|c|c|}
\hline \multirow[b]{2}{*}{ Isolate no. } & \multirow[b]{2}{*}{ VCG } & \multirow[b]{2}{*}{ Host origin } & \multirow[b]{2}{*}{ Geographic origin } & \multicolumn{2}{|c|}{ Mint species } & \multirow[b]{2}{*}{ Mean } \\
\hline & & & & $\begin{array}{c}\text { Black Mitcham } \\
\text { peppermint }\end{array}$ & $\begin{array}{c}\text { Scotch } \\
\text { spearmint }\end{array}$ & \\
\hline 123 & $2 \mathrm{~B}$ & Spearmint & WA & $5.4^{\mathrm{a}, \mathrm{b}}$ & 5.0 & $5.2^{\mathrm{c}}$ \\
\hline 29 & $2 \mathrm{~B}$ & Peppermint & MT & 5.8 & 4.5 & 5.1 \\
\hline 46 & $2 \mathrm{~B}$ & Spearmint & WA & 5.2 & 5.0 & 5.1 \\
\hline 104 & $2 \mathrm{~B}$ & Spearmint & WA & 6.0 & 4.5 & 5.1 \\
\hline 47 & $2 \mathrm{~B}$ & Spearmint & WA & 5.1 & 4.8 & 5.0 \\
\hline 21 & $2 \mathrm{~B}$ & Spearmint & WA & 4.9 & 4.9 & 4.9 \\
\hline 141 & $2 \mathrm{~B}$ & Peppermint & WA & 5.3 & 4.4 & 4.8 \\
\hline 84 & $2 \mathrm{~B}$ & Peppermint & WA & 5.5 & 4.0 & 4.8 \\
\hline 36 & $2 \mathrm{~B}$ & Peppermint & WA & 4.9 & 4.6 & 4.7 \\
\hline 151 & $2 \mathrm{~B}$ & Peppermint & OR & 5.3 & 4.1 & 4.7 \\
\hline 57 & $2 \mathrm{~B}$ & Spearmint & WA & 5.1 & 4.2 & 4.6 \\
\hline 75 & $2 \mathrm{~B}$ & Spearmint & WA & 4.7 & 4.5 & 4.6 \\
\hline 127 & $2 \mathrm{~B}$ & Spearmint & WA & 4.7 & 4.6 & 4.6 \\
\hline 136 & $2 \mathrm{~B}$ & Peppermint & MT & 4.6 & 4.3 & 4.4 \\
\hline 130 & $2 \mathrm{~B}$ & Spearmint & WA & 3.2 & 4.6 & 3.9 \\
\hline 49 & $2 \mathrm{~B}$ & Peppermint & WA & 4.0 & 4.1 & 3.9 \\
\hline 98 & $2 \mathrm{~B}$ & Spearmint & WA & 2.4 & 3.9 & 3.2 \\
\hline $868^{\mathrm{d}}$ & $2 \mathrm{~A}$ & Okra & $\mathrm{AK}$ & 2.8 & 3.0 & 2.7 \\
\hline 155 & $4 \mathrm{~A}$ & Peppermint & ID & 2.7 & 3.0 & 3.2 \\
\hline $601^{\mathrm{e}}$ & $4 \mathrm{~A}$ & Cherry & WA & 3.0 & 3.7 & 3.1 \\
\hline $629^{e}$ & $4 \mathrm{~A}$ & Potato & $\mathrm{BC}$ & 2.4 & 3.4 & 2.9 \\
\hline $653^{e}$ & $4 \mathrm{~A}$ & Potato & ID & 2.5 & 3.3 & 2.8 \\
\hline $97-147-2$ & $4 \mathrm{~A}$ & Watermelon & OR & 1.8 & 2.8 & 2.3 \\
\hline $\operatorname{LSD}(P=0.05)$ & & & & & & 0.9 \\
\hline
\end{tabular}

a All values were rounded to the nearest one-tenth.

b Symptoms recorded as $1=$ no visible symptoms to $6=$ dead or nearly dead.

c Treatment means were compared according to Fischer's protected LSD $(P<0.05)$.

d VCG designation of isolate 868 was determined by R. S. Potti and G. J. Weidemann, University of Arkansas, Fayetteville.

e Isolates were not included in the repeated experiment. 
published) showed no statistical difference between the two inoculum amounts; therefore, the amount of conidia used for experiments 2 to 4 was determined based on availability.

Plants were inoculated by uprooting them, gently shaking off soil, and soaking roots in $500 \mathrm{ml}$ of prepared conidial suspension for approximately $5 \mathrm{~min}$. Control plants were soaked in distilled water. All plants were planted in sterilized soil and placed in the greenhouse. Day-night temperatures for all experiments varied from 13 to $30^{\circ} \mathrm{C}$. Natural light was supplemented with sodium lamps to achieve a photoperiod of at least $15 \mathrm{~h}$. Light intensities ranged from 94 to $132 \mu \mathrm{E} \cdot \mathrm{m}^{-2} \cdot \mathrm{s}^{-1}$ PAR with sodium lights. After transplanting, mint plants were cut back to 1 to $2 \mathrm{~cm}$ above the soil line to promote new shoot growth.

Verticillium wilt symptoms were assessed in mint just before flowering at approximately 6 to 8 weeks after inoculation. After disease evaluations were made, stems were cut near the soil line and plants were allowed to regrow. Wilt severity was assessed again just before flowering at approximately 14 to 16 weeks after inoculation. The cutting and regrowth simulated seasonal harvest of perennial mint plants in the field and allowed time for continued wilt development. The rating scale used for Verticillium wilt of mint was as follows: $1=$ no visible symptoms; $2=$ slight chlorosis of upper leaves; $3=1$ to $30 \%$ of foliage with slight chlorosis of upper leaves and mild stunting; $4=31$ to $60 \%$ of foliage with extensive chlorosis of upper leaves, moderate stunting, and few to many crescent leaves; $5=>60 \%$ of foliage with severe chlorosis of upper leaves, severe stunting, and many crescent leaves; $6=$ plants dead or nearly dead. Potato plants were evaluated for wilt symptoms four times at 7-day intervals to determine disease progression. The initial rating was taken at disease onset at 30 and 16 days after planting for the first and second repetition, respectively. The rating scale used for Verticillium wilt of potato was: $1=$ no visible symptoms; 2 = slight chlorosis of upper leaves and slight stunting; $3=$ slight chlorosis of upper leaves and mild stunting; 4 = extensive chlorosis of upper leaves and moderate stunting; $5=$ chlorosis of upper and lower leaves; $6=$ plants dead or nearly dead. Areas under the senescence progress curves (AUSPC) were calculated using wilt severity values $(7,22)$ using the following formula:

$$
\sum_{i}^{n-1}\left(\frac{Y_{i}+Y_{i+1}}{2}\right)\left(t_{i+1}-t_{i}\right)
$$

where $Y_{i}=$ the cumulative disease severity at the $i$ th observation, $t_{i}=$ time (days postinoculation) at the $i$ th observation, and $n=$ the total number of observations.

All mint stems after the first rating and potato stems after the final rating were assayed for the presence of $V$. dahliae by the same method used initially to obtain $V$. dahliae isolates. If plants were dead, stems were surfaced-sterilized with $10 \%$ commercial bleach solution, rinsed in sterile water, and placed on moist filter paper in a glass petri dish. After 5 to 7 days, dead stems were examined for the presence of verticillate conidiophores or microsclerotia.

All experiments were analyzed independently using SAS, v 6.12 (SAS Institute, Cary, NC). The first and the repeat of each experiment were not combined due to statistical interaction between experiments. Mint data were analyzed as a split-plot in time using PROC GLM. Main plots were the mint species and isolates, and subplots

Table 2. Mean disease severity values when spearmint and peppermint were inoculated with Verticillium dahliae isolates VCG 2B and VCG 4A from mint and other hosts in experiment 2

\begin{tabular}{|c|c|c|c|c|c|c|}
\hline \multirow[b]{2}{*}{ Isolate no. } & \multirow[b]{2}{*}{ VCG } & \multirow[b]{2}{*}{ Host origin } & \multirow[b]{2}{*}{ Geographic origin } & \multicolumn{2}{|c|}{ Mint species } & \multirow[b]{2}{*}{ Mean } \\
\hline & & & & $\begin{array}{c}\text { Black Mitcham } \\
\text { peppermint }\end{array}$ & $\begin{array}{c}\text { Scotch } \\
\text { spearmint }\end{array}$ & \\
\hline 102 & $2 \mathrm{~B}$ & Peppermint & WA & $4.5^{\mathrm{a}, \mathrm{b}}$ & 3.8 & $4.2^{\mathrm{c}}$ \\
\hline 83 & $2 \mathrm{~B}$ & Peppermint & WA & 4.7 & 3.9 & 4.3 \\
\hline 82 & $2 \mathrm{~B}$ & Peppermint & WA & 4.9 & 4.3 & 4.5 \\
\hline 113 & $2 \mathrm{~B}$ & Peppermint & WA & 4.9 & 3.8 & 4.4 \\
\hline 601 & $4 \mathrm{~A}$ & Cherry & WA & 1.6 & 2.3 & 2.0 \\
\hline 608 & $4 \mathrm{~A}$ & Potato & WA & 1.6 & 2.3 & 2.0 \\
\hline $629^{\mathrm{d}}$ & $4 \mathrm{~A}$ & Potato & $\mathrm{BC}$ & 2.2 & 1.9 & 2.0 \\
\hline 653 & $4 \mathrm{~A}$ & Potato & ID & 2.0 & 1.8 & 1.9 \\
\hline $\operatorname{LSD}(P=0.05)$ & & & & & & 0.7 \\
\hline
\end{tabular}

a All values were rounded to the nearest one-tenth.

b Symptoms recorded as $1=$ no visible symptoms to $6=$ dead or nearly dead.

c Treatment means were compared according to Fisher's protected LSD $(P<0.05)$.

${ }^{\mathrm{d}}$ Isolates were not included in the repeated experiment.

Table 3. Mean disease severity values when spearmint and peppermint were inoculated with Verticillium dahliae isolates VCG 2B, 2X, 2, and VCG 4A from mint and other hosts in experiment 3

\begin{tabular}{|c|c|c|c|c|c|c|}
\hline \multirow[b]{2}{*}{ Isolate no. } & \multirow[b]{2}{*}{ VCG } & \multirow[b]{2}{*}{ Host origin } & \multirow[b]{2}{*}{ Geographic origin } & \multicolumn{2}{|c|}{ Mint species } & \multirow[b]{2}{*}{ Mean } \\
\hline & & & & $\begin{array}{c}\text { Black Mitcham } \\
\text { peppermint }\end{array}$ & $\begin{array}{c}\text { Scotch } \\
\text { spearmint }\end{array}$ & \\
\hline 50 & $2 B$ & Peppermint & WA & $4.9^{\mathrm{a}, \mathrm{b}}$ & 4.3 & $4.6^{\mathrm{c}}$ \\
\hline 79 & $2 \mathrm{~B}$ & Peppermint & WA & 5.1 & 3.3 & 4.2 \\
\hline 109 & $2 \mathrm{~B}$ & Peppermint & WA & 5.3 & 3.1 & 4.2 \\
\hline 155 & $4 \mathrm{~A}$ & Peppermint & ID & 3.9 & 2.2 & 3.1 \\
\hline St81 & $2 X^{\mathrm{d}}$ & Potato & ID & 1.9 & 1.8 & 1.9 \\
\hline Le78 & $2 X^{\mathrm{d}}$ & Tomato & $\mathrm{CA}$ & 1.3 & 1.3 & 1.3 \\
\hline Fca29 & $2 X^{d}$ & Strawberry & $\mathrm{CA}$ & 1.4 & 1.6 & 1.5 \\
\hline Ca35 & $2^{\mathrm{d}}$ & Bell pepper & $\mathrm{CA}$ & 1.8 & 2.0 & 1.9 \\
\hline $\operatorname{LSD}(P=0.05)$ & & & & & & 0.9 \\
\hline
\end{tabular}

a All values were rounded to the nearest one-tenth.

${ }^{\mathrm{b}}$ Symptoms recorded as $1=$ no visible symptoms to $6=$ dead or nearly dead.

c Treatment means were compared according to Fisher's protected LSD $(P<0.05)$.

${ }^{\mathrm{d}}$ VCG designation of VCG $2 \mathrm{X}$ and 2 were determined by K. Subbarao, University of CA, Davis, CA, Agricultural Research Station, Sal inas, CA. 
were disease ratings from the first and second growth. Split-plot analysis was used to obtain information on the differences between the disease ratings of the two growing periods. AUSPC data from the potato experiment were analyzed as a one-way analysis of variance (ANOVA). Single degree of freedom contrasts were used to test differences among treatment means. Fisher's protected LSD at $P=0.05$ was used to compare treatment means.

\section{RESULTS}

Vegetative compatibility. All $128 \mathrm{mint}$ isolates tested were assigned to two VCGs; 125 to VCG $2 \mathrm{~B}$, one to VCG $2 \mathrm{~A}$, and two to VCG 4A. Among the two phenotypic classes of nit mutants recognized, $70 \%$ exhibited wild-type growth on all nitrogen sources except nitrate and thus were considered nit 1 . The remaining 30\% exhibited wild-type growth on all nitrogen sources except hypoxanthine and nitrate and thus were considered NitM. No prototrophic growth occurred between the testers and eight randomly selected mutants when separated by a membrane, demonstrating that the positive reactions were the result of heterokaryon formation and not crossfeeding.

Pathogenicity assays. All mint pathogenicity experiments showed that when inoculated to mint, isolates from mint were collectively more aggressive $(P<0.05)$ than those isolates from other hosts (Tables
1 to 3$)$. For experiment 1 , there were significant $(P<0.05)$ differences among the mint isolates and among the isolates from other hosts (Table 1). The results were the same when the experiment was repeated. For experiment 2, there were no significant $(P>0.05)$ differences among the four mint isolates or among the isolates from potato and cherry (Table 2). The results were the same when the experiment was repeated. In experiment 3 , there were no statistical $(P>0.05)$ differences among the VCG 2B mint isolates in the first part, but in the repeat there were significant $(\mathrm{P}<0.05)$ differences among the VCG $2 \mathrm{~B}$ mint isolates. However, VCG $2 \mathrm{~B}$ consistently produced more disease than isolate 155 from mint belonging to VCG $4 \mathrm{~A}$ of the first (Table 3 ) and the repeat of experiment 3.

Disease symptoms were usually more severe on Black Mitcham peppermint than on Scotch spearmint. No statistical $(P>$ $0.05)$ differences were found between the two mint species in the first part of experiment 1 , but in the repeat, Scotch spearmint had significantly $(P<0.05)$ more disease than Black Mitcham peppermint. In experiments 2 and 3, Black Mitcham peppermint had significantly $(P<$ 0.05) more disease than Scotch spearmint for the first part of the experiment and the repeat (Table 5). For all the mint experiments, wilt severity was significantly $(P<$ $0.05)$ more severe when mint plants were allowed to regrow after being cut to simu-

Table 4. Mean area under the senescence progress curve (AUSPC) values when potato cultivar Russet Norkotah was inoculated with Verticillium dahliae isolates from mint and potato belonging to VCG 2, 4A, and 4B in experiment 4

\begin{tabular}{|c|c|c|c|c|c|}
\hline \multirow[b]{2}{*}{ Isolate no. } & \multirow[b]{2}{*}{ VCG } & \multirow{2}{*}{$\begin{array}{c}\text { Geographic } \\
\text { origin }\end{array}$} & \multirow[b]{2}{*}{ Host origin } & \multicolumn{2}{|c|}{ Experiment 4 AUSPC } \\
\hline & & & & $\mathbf{4 A}$ & 4B \\
\hline 145 & $2 \mathrm{~B}$ & WA & Peppermint & $29.1^{b, c}$ & $\mathrm{NT}^{\mathrm{d}}$ \\
\hline 83 & $2 \mathrm{~B}$ & WA & Peppermint & 30.8 & 21.4 \\
\hline 82 & $2 \mathrm{~B}$ & WA & Peppermint & 37.8 & 21.0 \\
\hline 653 & $4 \mathrm{~A}$ & ID & Potato & 88.9 & 112.4 \\
\hline 155 & $4 \mathrm{~A}$ & ID & Peppermint & 102.9 & 109.8 \\
\hline 233 & $4 \mathrm{~A}$ & $\mathrm{OH}$ & Potato & 66.2 & 104.1 \\
\hline 235 & $4 \mathrm{~B}$ & $\mathrm{OH}$ & Potato & NT & 77.9 \\
\hline 239 & 4B & $\mathrm{OH}$ & Potato & 32.2 & 52.5 \\
\hline $\operatorname{LSD}(P=0$. & & & & 17.1 & 15.2 \\
\hline
\end{tabular}

a AUSPC $=\sum_{i}^{n-1}\left[\left(Y_{i}+Y_{i+1}\right) / 2\right]\left(t_{i+1}-t_{i}\right)$ where $Y_{i}=$ the cumulative disease severity at the $i$ th observation, $t_{i}$ $=$ time (days postinoculation) at the $i$ th observation, and $n=$ the total number of observations.

${ }^{\mathrm{b}}$ Symptoms recorded as $1=$ no visible symptoms to $6=$ dead or nearly dead.

${ }^{c}$ Values with the same letter for one experiment are not significantly different (LSD $P>0.05$ ).

${ }^{\mathrm{d}} \mathrm{NT}=$ not tested

Table 5. Comparisons of mean disease severity values of Black Mitcham peppermint and Scotch spearmint for experiment 1,2 , and 3

\begin{tabular}{|c|c|c|c|c|c|c|}
\hline \multirow[b]{2}{*}{ Mint species } & \multicolumn{2}{|c|}{ Experiment 1} & \multicolumn{2}{|c|}{ Experiment 2} & \multicolumn{2}{|c|}{ Experiment 3} \\
\hline & First & Repeat & First & Repeat & First & Repeat \\
\hline $\begin{array}{l}\text { Black Mitcham } \\
\text { peppermint }\end{array}$ & $4.20^{\mathrm{a}, \mathrm{b}, \mathrm{c}}$ & 3.32 & 3.30 & 2.72 & 3.21 & 1.99 \\
\hline Scotch spearmint & 4.11 & 3.78 & 3.01 & 2.17 & 2.45 & 1.67 \\
\hline $\operatorname{LSD}(P=0.05)$ & 0.25 & 0.43 & 0.33 & 0.36 & 0.38 & 0.26 \\
\hline
\end{tabular}

${ }^{a}$ All values were rounded to the nearest one-hundredth.

${ }^{\text {b }}$ Symptoms recorded as $1=$ no visible symptoms to $6=$ dead or nearly dead.

c Treatment means were compared according to Fisher's protected LSD $(P<0.05)$. late seasonal harvests, reflecting the increased wilt often seen in the field with successive cuttings.

When inoculated to potato, potato and mint VCG 4A isolates were significantly $(P<0.05)$ more aggressive than mint VCG $2 \mathrm{~B}$ or potato VCG $4 \mathrm{~B}$, as indicated by the AUSPC values. Using single degree of freedom contrasts, the VCG 4A isolates were significantly $(P<0.05)$ more aggressive on potato than VCG $2 \mathrm{~A}$ and $\mathrm{VCG} 4 \mathrm{~B}$ isolates. When the experiment was repeated, all three VCGs differed significantly $(P<0.05)$ from one another; however, VCG 4A again was significantly $(P<$ $0.05)$ more aggressive than the other VCGs (Table 4).

\section{DISCUSSION}

VCG diversity among $128 \mathrm{~V}$. dahliae isolates from naturally infected spearmint and peppermint was low, with $98 \%$ of $V$. dahliae isolates belonging to a single VCG. The two isolates assigned to VCG $4 \mathrm{~A}$ were collected in southern Idaho, whereas the VCG 2B and VCG 2A isolates were collected throughout the Pacific Northwest and northern Midwest, thus demonstrating the widespread distribution of VCG 2B on mint. These results agree with previous studies that have demonstrated low overall VCG diversity within $V$. dahliae within a particular host $(29,33)$.

The predominance and widespread distribution of the VCG 2B mint strain may be attributed to asexual reproduction of $V$. dahliae, vegetative propagation of mint, and the relatively rapid shift of mint production from the U.S. Midwest to the Pacific Northwest. Since sexual reproduction is unknown in $V$. dahliae, it is unlikely that vegetative compatibility genes are recombining. Thus, VCG 2B strains may belong to a subpopulation genetically isolated from other VCGs (24), and the mint isolates may represent a clonal lineage. We speculate that a single strain of $V$. dahliae may have become disseminated in mint rhizomes from the Midwest during the late 1920 s to the 1940 s when the price of mint oil greatly increased and mint production expanded to the Pacific Northwest (23). Omer et al. (29) found similar results with $V$. dahliae from certified seed potatoes. Their study showed that VCG 4 was the only VCG recovered from the 162 isolates examined with more than half of the western and two-thirds of the eastern isolates belonging to VCG 4A.

$V$. dahliae is considered to have a wide host range; however, there are documented examples suggesting host-adapted isolates $(1,10,22,29,34,36)$. Isolates within $V$. dahliae are considered to be host-adapted rather than host-specific since the isolates can potentially infect a wide range of hosts but often seem to be adapted as an aggressive pathogen only on certain hosts. In contrast, host-specific isolates by definition are able to infect only certain hosts. This 
study demonstrates that mint isolates are not host-specific since mint isolates cause wilt on potatoes (Table 4) and isolates from several hosts can cause slight disease on mint (Tables 1 to 3 ). However, mint isolates should be considered host-adapted and probably comprise a distinct pathotype since they are collectively more aggressive on mint than isolates from other hosts.

Correlations between pathotype and VCG have been reported for $V$. dahliae $(11,22,29,36)$. Joaquim and Rowe (22) determined that isolates within VCG 4A represented a distinct pathotype since they were collectively more aggressive on potatoes than isolates belonging to either VCG $4 \mathrm{~B}$ or VCG 2. This study showed similar results. One VCG 4A isolate from mint and two from potato were more aggressive to the potato cultivar Russet Norkotah than VCG 4B isolates from potato and VCG 2 isolates from mint (Table 4). Botseas and Rowe (5) further distinguished VCG 4A isolates from VCG 4B isolates by demonstrating that on potato the root lesion nematode, Pratylenchus penetrans, interacted synergistically with VCG 4A $V$. dahliae isolates but either did not interact or did so only slightly with VCG 4B isolates. Schnarthorst and Mathre (34) designated two pathotypes, cotton defoliating and cotton nondefoliating, but Ashworth (2) suggested that there was a continuum of virulence among isolates from cotton rather than two distinct pathotypes. Daayf et al. (11) confirmed the correlation between VCG and the two cotton pathotypes by showing that the defoliating isolates belonged to VCG 1 and the nondefoliating isolates belonged to VCG 2 and VCG 4. Based solely on restriction fragment length polymorphism (RFLP) markers, a distinct host-adapted group from peppermint was recognized (28).

The two mint isolates from this study that belonged to VCG 4A were collected from diseased mint plants in two separate counties in southern Idaho. One of these isolates, 155, was obtained from a firstyear mint field that previously had been cropped to potato but never to mint. The planting material originated from stem cuttings produced in sterile soil from Verticillium-free mother plants grown in a greenhouse. The stem cuttings were intended for rhizome certification for planting stock and are unlikely to have been the source of the $V$. dahliae isolate. It is more likely that this isolate originated from potato residue in the soil from the previous crop. When inoculated to potato, isolate 155 produced severe symptoms similar to those produced by other VCG 4A isolates from potato.

VCG analysis of $V$. dahliae from mint in this study agrees with previous observations that VCG diversity within $V$. dahliae is limited $(3,8,11,13,21,22,26,29,30,32$, $37,38)$. The low VCG diversity in mint isolates may be the result of the introduction and proliferation of a single aggressive strain via infected rhizomes. Pathogenicity experiments suggest that isolates from mint are a distinct pathotype since they are more aggressive on mint than isolates from other hosts. Knowledge of the presence of specific $V$. dahliae strains within mint rhizome planting stock or in the soil may be useful in selecting specific crop rotations involving mint and other crops susceptible to $V$. dahliae.

\section{ACKNOWLEDGMENTS}

Plant Pathology New Series 0301, Department of Plant Pathology, College of Agriculture and Home Economics Research Center Project No. 0301, Washington State University, Pullman 99164-6430. We thank the Washington Mint Commission for funding this research. We thank R. C. Rowe for the discussion that lead to the development of this work and assistance with the VCG analysis. We appreciate L. Carris, T. Peevers, and R. C. Rowe for the valuable comments and suggestions for the manuscript. We would also like to thank R. S. Potti, G. J. Weidemann, and K. Subbarao for the isolates given for pathogenicity experiments and B. Geary and D. Vargas for the laboratory support.

\section{LITERATURE CITED}

1. Alexander, L. J. 1962. Susceptibility of certain Verticillium-resistant tomato varieties to an Ohio isolate of the pathogen. Phytopathology 52:998-1000.

2. Ashworth, L. J., Jr. 1983. Aggressiveness of random and selected isolates of Verticillium dahliae from cotton and the quantitative relationship of internal inoculum to defoliation. Phytopathology 73:1292-1295.

3. Bao, J. R., Katan, J., Shabi, E., and Katan, T. 1998. Vegetative-compatibility groups in Verticillium dahliae from Israel. Eur. J. Plant Pathol. 104:263-269.

4. Berry, S. Z., and Thomas, C. A. 1960. Influence of soil temperature, isolates, and method of inoculation on resistance of mint to Verticillium wilt. Phytopathology 51:169-174.

5. Botseas, D. D., and Rowe, R. C. 1994. Development of potato early dying in response to infection by two pathotypes of Verticillium dahliae and co-infection of Pratylenchus penetrans. Phytopathology 84:275-282.

6. Butterfield, E. J., and DeVay, J. E. 1977. Reassessment of soil assays for Verticillium dahliae. Phytopathology 67:1073-1078.

7. Campbell, C. L., and Madden, L. V. 1990. Introduction of Plant Disease Epidemiology. John Wiley \& Sons, New York.

8. Chen, W. 1994. Vegetative compatibility groups of Verticillium dahliae from ornamental woody plants. Phytopathology 84:214219.

9. Correll, J. C., Klittich, C. J., and Leslie, J. F. 1987. Nitrate non-utilizing mutants of Fusarium oxysporum and their use in vegetative compatibility tests. Phytopathology 77:1640-1646.

10. Corsini, D. L., Davis, J. R., and Pavek, J. J. 1985. Stability of resistance of potato to strains of Verticillium dahliae from different vegetative compatibility groups. Plant Dis. 69:980-982.

11. Daayf, F., Nicole, M., and Geiger, J.-P. 1995. Differentiation of Verticillium dahliae populations on the basis of vegetative compatibility and pathogenicity on cotton. Eur. J. Plant Pathol. 101:69-79.

12. Douhan, L. I., and Johnson, D. A. 1998. Vegetative compatibility and pathogenicity of Verticillium dahliae isolates from spearmint and peppermint. (Abstr.) Phytopathology 88:S23.

13. Elena, K., and Paplomatas, E. J. 1998. Vegetative compatibility groups within Verticillium dahliae isolates from different hosts in Greece. Plant Pathol. 47:635-640.

14. Fordyce, C., Jr., and Green, R. J., Jr. 1963. Alteration of pathogenicity of Verticillium albo-atrum var. menthae. Phytopathology 53:701-704.

15. Green, R. J. 1951. Studies on the host range of the Verticillium that causes wilt of Mentha piperita L. Science 113:207-208.

16. Green, R. J., Jr. 1967. Control of Verticillium wilt of peppermint by crop rotation sequences. Plant Dis. Rep. 51:441-453.

17. Green, R. J., Jr. 1977. Alteration of pathogenicity of Verticillium dahliae from Mentha sp. under field conditions. Plant Dis. Rep. 61:373-374.

18. Hawksworth, D. L., and Talboys, P. W. 1970. Verticillium dahliae. CMI Descr. Pathog. Fungi Bact. 256. 2 p.

19. Horner, C. E. 1954. Pathogenicity of Verticillium isolates to peppermint. Phytopathology 44:239-242.

20. Joaquim, T. R. 1989. Vegetative compatibility analysis and comparative pathogenicity to potato of soil and potato plant isolates of Verticillium dahliae. Ph.D. thesis. Ohio State University, Wooster.

21. Joaquim, T. R., and Rowe, R. C. 1990. Reassessment of vegetative compatibility relationships among strains of Verticillium dahliae using nitrate-nonutilizing mutants. Phytopathology 80:1160-1166.

22. Joaquim, T. R., and Rowe, R. C. 1991. Vegetative compatibility and virulence of strains of Verticillium dahliae from soil and potato plants. Phytopathology 81:552-558.

23. Landing, J. E. 1960. American Essence: A history of peppermint and spearmint industry in the United States. Kalamazoo Public Museum, Kalamazoo, MI. p. 244.

24. Leslie, J. F. 1993. Fungal vegetative compatibility. Annu. Rev. Phytopathol. 31:127-150.

25. Morrell, A., Schreiber, A., and Lundy, R. 1997. Pests, pest control, and fertilizer use in Washington mint. Washington State University Cooperative Extension, MISC0188, Pullman.

26. Nagao, H., Hiroaki, A., Oshima, S., Koike, M., and Iijima, T. 1998. Vegetative compatibility of an isolate of Verticillium dahliae pathogenic to both tomato and pepper. Mycoscience 39:37-42

27. Nelson, R. 1950. Verticillium wilt of Peppermint (Mentha piperita L.). Mich. Agric. Exp. Stn. Tech. Bull. 221.

28. Okoli, C. A. N., Carder, J. H., and Barbara, D. J. 1994. Restriction fragment length polymorphisms (RFLPs) and the relationships of some host-adapted isolates of Verticillium dahliae. Plant Pathol. 43:33-40.

29. Omer, M. A., Johnson, D. A., and Rowe, R. C. Recovery of Verticillium dahliae from $\mathrm{N}$. American certified seed potatoes and characterization of strains by vegetative compatibility and aggressiveness. Am. J. Potato Res. In press.

30. Puhalla, J. E. 1979. Classification of isolates of Verticillium dahliae based on heterokaryon incompatibility. Phytopathology 69:11861189

31. Puhalla, J. E. 1985. Classification of strains of Fusarium oxysporum on the basis of vegetative compatibility. Can. J. Bot. 63:179183.

32. Puhalla, J. E., and Hummel, H. 1983. Vegetative compatibility groups within Verticillium dahliae. Phytopathology 73:1305-1308.

33. Rowe, R. C. 1995. Recent progress in understanding relationships between Verticillium 
species and subspecific groups. Phytoparasitica 23:31-38.

34. Schnarthorst, W. C., and Mathre, D. E. 1966. Host range and differentiation of a severe form of Verticillium albo-atrum in cotton. Phytopathology 56:1155-1161.

35. Strausbaugh, C. A. 1993. Assessment of vegetative compatibility and virulence of Verticillium dahliae from Idaho potatoes and tester strains. Phytopathology 83:61-68.

36. Strausbaugh, C. A., Schroth, M. N., Weinhold, A. R., and Hancock, J. G. 1992. Assessment of vegetative compatibility of Verticillium dahliae tester strains and isolates from California potatoes. Phytopathology 82:61-68.

37. Subbarao, K. V., Chassot, A., Gordon, T. R., Hubbard, J. C., Bonello, P., Mullin, R., Okamoto, D., Davis, R. M., and Koike, S. T.
1995. Genetic relationships and cross pathogenicities of Verticillium dahliae isolates from cauliflower and other crops. Phytopathology 85:1105-1112.

38. Wakatabe, D., Nagao, H., Hiroaki, A. Shiraishi, T., Koike, M., and Iijima, T. 1997. Vegetative compatibility groups of Japanese isolates of Verticillium dahliae. Mycoscience $38: 17-23$. 